\title{
Communication
}

\section{Improved Light Harvesting of Fiber-Shaped Dye-Sensitized Solar Cells by Using a Bacteriophage Doping Method}

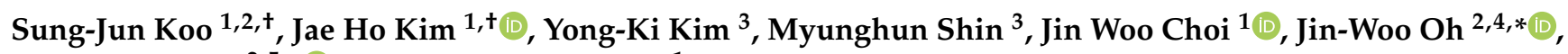 \\ Hyung Woo Lee ${ }^{2,5, * \mathbb{C}}$ and Myungkwan Song ${ }^{1, *}$ \\ 1 Department of Energy and Electronic Materials, Korea Institute of Materials Science (KIMS), \\ Changwon 51508, Korea; sungun666@kims.re.kr (S.-J.K.); jho83@kims.re.kr (J.H.K.); \\ jinwoo.choi@kims.re.kr (J.W.C.) \\ 2 Department of Nano Fusion Technology, Pusan National University, Busan 46241, Korea \\ 3 School of Electronics and Information Engineering, Korea Aerospace University, Goyang 10540, Korea; \\ ygk3373@kau.kr (Y.-K.K.); mhshin@kau.ac.kr (M.S.) \\ 4 Bio-IT Fusion Technology Research Institute, Pusan National University, Busan 46241, Korea \\ 5 Department of Nanoenergy Engineering and Research Center of Energy Convergence Technology, \\ Pusan Natuional University, Busan 46241, Korea \\ * Correspondence: ojw@pusan.ac.kr (J.-W.O.); LHW2010@pusan.ac.kr (H.W.L.); smk1017@kims.re.kr (M.S.) \\ + These authors contributed equally to this work.
}

check for

updates

Citation: Koo, S.-J.; Kim, J.H.; Kim, Y.-K.; Shin, M.; Choi, J.W.; Oh, J.-W.; Lee, H.W.; Song, M. Improved Light Harvesting of Fiber-Shaped Dye-Sensitized Solar Cells by Using a Bacteriophage Doping Method. Nanomaterials 2021, 11, 3421. https://doi.org/10.3390/ nano11123421

Academic Editors: Sophie Tingry, Marc Cretin and Zhenghua Tang

Received: 26 November 2021 Accepted: 14 December 2021 Published: 17 December 2021

Publisher's Note: MDPI stays neutral with regard to jurisdictional claims in published maps and institutional affiliations.

Copyright: (c) 2021 by the authors. Licensee MDPI, Basel, Switzerland. This article is an open access article distributed under the terms and conditions of the Creative Commons Attribution (CC BY) license (https:/ / creativecommons.org/licenses/by/ $4.0 /)$.

\begin{abstract}
Fiber-shaped solar cells (FSCs) with flexibility, wearability, and wearability have emerged as a topic of intensive interest and development in recent years. Although the development of this material is still in its early stages, bacteriophage-metallic nanostructures, which exhibit prominent localized surface plasmon resonance (LSPR) properties, are one such material that has been utilized to further improve the power conversion efficiency (PCE) of solar cells. This study confirmed that fiber-shaped dye-sensitized solar cells (FDSSCs) enhanced by silver nanoparticles-embedded M13 bacteriophage (Ag@M13) can be developed as solar cell devices with better PCE than the solar cells without them. The PCE of FDSSCs was improved by adding the Ag@M13 into an iodine species $\left(\mathrm{I}^{-} / \mathrm{I}_{3}{ }^{-}\right)$based electrolyte, which is used for redox couple reactions. The optimized Ag@M13 enhanced FDSSC showed a PCE of up to $5.80 \%$, which was improved by $16.7 \%$ compared to that of the reference device with $4.97 \%$.
\end{abstract}

Keywords: fiber-shaped solar cells; dye-sensitized solar cells; M13 bacteriophage; plasmon resonance

\section{Introduction}

Harvesting solar energy has been regarded as one of the easiest solutions to collect the promising renewable energy resources for sustainable development. Among various flexible energy harvesting technologies, fiber-shaped dye-sensitized solar cells (FDSSCs), which represent a promising future energy source with flexible and wearable properties, are drawing the attention of many researchers because it is lightweight, inexpensive, simple to manufacture, and flexible [1-7]. The FDSSCs typically consist of three parts: a photoanode (PA), a counter electrode (CE), and a redox electrolyte. Under illumination, dyes act as photosensitizer, in which photons excite electrons at the highest occupied molecular orbital (HOMO) to the lowest unoccupied molecular orbital (LUMO). The excited electrons are injected into the conduction band of the PA and then diffused through the PA into the electrode to reach the $\mathrm{CE}$ through an external circuit. On one hand, iodide $\left(\mathrm{I}^{-}\right)$, a reductive species in the electrolyte, supplies electrons to the oxidized dye and becomes triiodide $\left(\mathrm{I}_{3}{ }^{-}\right)$, which in turn gains electrons from the CE to complete the redox couple $[8,9]$.

The electrolyte is one of the most important components of dye-sensitized solar cells (DSSCs) and has a significant impact on the high power conversion efficiency (PCE) in solar cells. The electrolyte in solar cell devices should have the following characteristics: (I) It should be able to regenerate the oxidized dye efficiently. (II) Should not corrode with 
DSSC components. (III) Should rapidly diffuse charge carriers, improve conductivity, and enable effective contact between the working and counter electrodes. (IV) Absorption spectra of an electrolyte should not overlap with the absorption spectra of a dye $[10,11]$. Therefore, to satisfy the above functions, bacteriophage-metallic nanostructures, which exhibit prominent localized surface plasmon resonance (LSPR) properties, were integrated with the iodine species $\left(\mathrm{I}^{-} / \mathrm{I}_{3}{ }^{-}\right)$based electrolyte that has been proven as a highly efficient electrolyte. The metallic nanoparticles (NPs) mainly increase the light-surface plasmon coupling, realizing a plasmonic enhancement effect in photoelectric devices [12]. Hence, incorporating bacteriophage-metallic nanostructures into on unit of solar cells is a promising alternative strategy that can improve the performance of photoelectric devices by inducing the LSPR properties, which is receiving great attention for light scattering, fluorescence, charge transfer, and local field enhancement [13-15].

Recently, among the bacteriophage-metallic nanostructures, an M13 bacteriophage has attracted particular attention due to its non-toxic, self-assembly, and specific binding properties. This bacterial virus, M13 bacteriophage, is $880 \mathrm{~nm}$ in length and $6.6 \mathrm{~nm}$ in diameter, consisting of a single-stranded DNA molecule enclosed by 2700 identical copies of the major coat protein $\mathrm{pVIII}$ and capped with five copies of four different minor coat proteins at the ends [16], as shown in Figure 1a. The M13 bacteriophage is easily applicable to wearable applications because it is stable in a wide range of $\mathrm{pH}[17,18]$ and temperatures and organic solvents $[19,20]$ and is not injurious to humans or animals. In addition, since the functionalization such as easily attaching metal ions to the DNA surface, there is a possibility that it can be applied to various fields of electronic devices [21,22]. Previous study reported plasmon-enhanced light absorption, photocurrent density and PCE by incorporating metallic NPs into mesoporous $\mathrm{TiO}_{2}\left(\mathrm{mp}-\mathrm{TiO}_{2}\right)$ and electrolyte interface $[23,24]$. However, these plasmonic DSSCs have the critical issues when metal NPs were incorporated into the liquid electrolyte such as the aggregation of NPs [25]. For photoelectric applications, M13 bacteriophage-metallic nanostructure conjugates can be an excellent platform because M13 is easily fictionalized with metallic NPs by using phage display technology [26].

Herein, the M13 bacteriophage, which has improved the LSPR properties by anchoring of metallic silver (Ag) NPs, was added to the electrolyte of the solar cell. The electrolyte improved with an Ag NPs-embedded M13 bacteriophage (Ag@M13) showed a high absorbance in a long wavelength region of $500 \mathrm{~nm}$ or more, confirming that the plasmonic Ag NPs were uniformly oriented and aligned in nanoscale M13 bacteriophages. Furthermore, the FDSSCs were fabricated using an enhanced electrolyte supplemented with Ag@M13, which was demonstrated to improve the PCE by plasmonic enhancement effect. The optimized Ag@M13 enhanced FDSSC boasts effective electron extraction, unidirectional electron transportation, and suppressed charge recombination processes, resulting in a PCE of up to $5.80 \%$, which was improved by $16.7 \%$ compared to that of the reference device with $4.97 \%$.

\section{Materials and Methods}

\subsection{Materials}

Titanium wire ( $\phi 250 \mu \mathrm{m}, 99.7 \%$ ) was purchased from Sigma-Aldrich (Burlington, MA, U.S.). $\mathrm{TiO}_{2}$ paste (18NR-T) and iodine species $\left(\mathrm{I}^{-} / \mathrm{I}_{3}{ }^{-}\right)$based High Performance Electrolyte (HPE) were purchased from Greatcellsolar (Queanbeyan, Australia). Y123 dye (DN-F05Y) was purchased from Dyenamo (Stockholm, Sweden). Platinum wire ( $\phi 125 \mu \mathrm{m}, 99.9 \%)$ was manufactured by a Wooillmetal (Yongin, South Korea). 

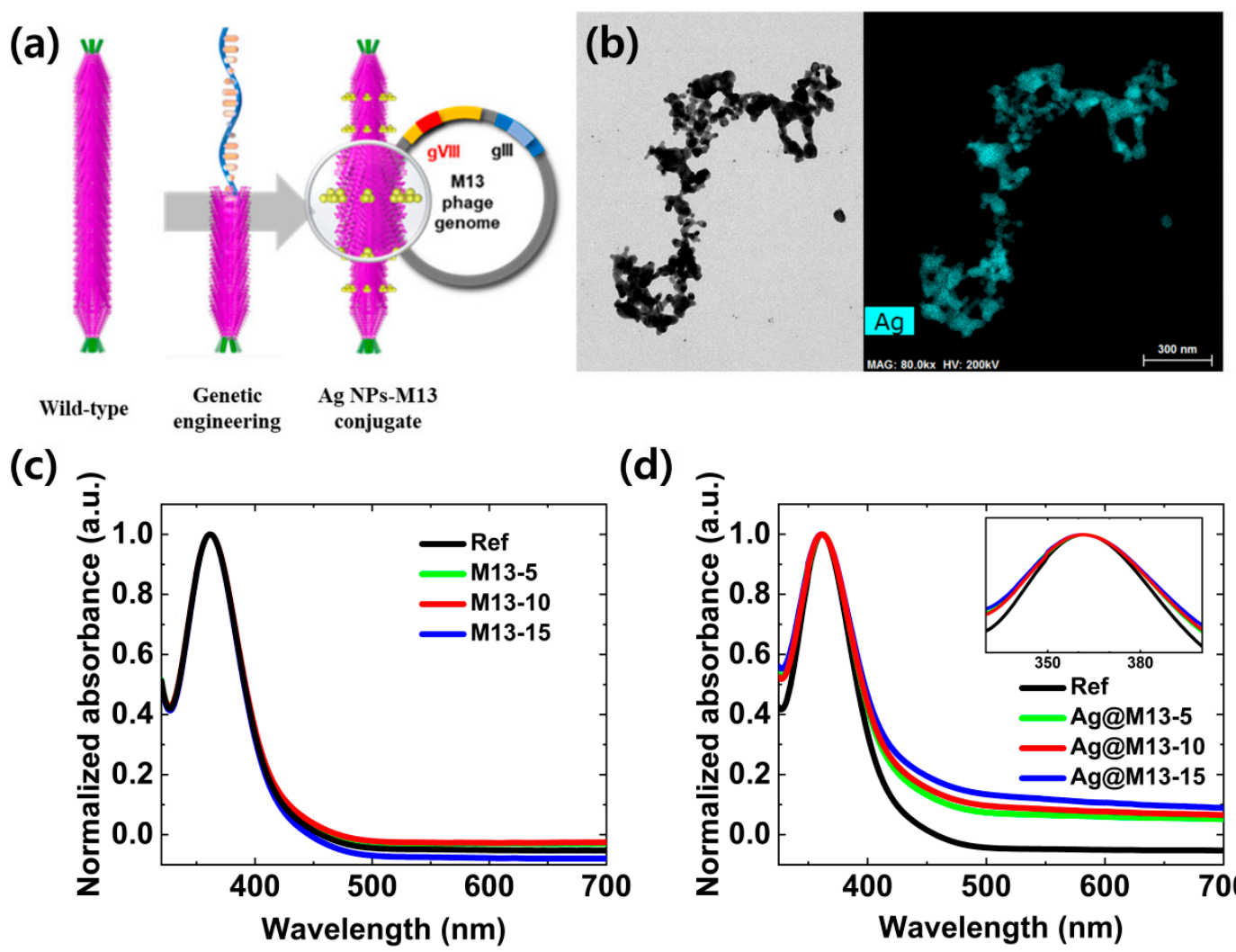

(d)

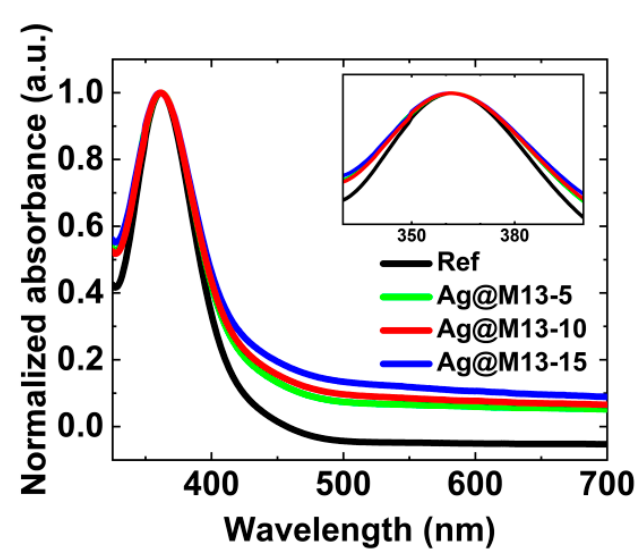

Figure 1. Morphological and optical characteristics of Ag@M13 bacteriophage: (a) schematic representation with structure on Ag@M13, (b) HR-TEM image (left) of morphology of Ag@M13 and EDS-STEM (right) to investigate its elemental mapping spectra, (c) normalized absorbance of as a function of M13 bacteriophage without Ag NPs, and (d) normalized absorbance of as a function of Ag@M13 bacteriophage. The inset is a high magnification of the main absorbance peak.

\subsection{Optical Simulation of $A g-B P-D S S C$}

The light scattering effect by Ag particles for a DSSC is simulated in the following way. The elemental samples of an electrolyte layer $(60 \mu \mathrm{m})$ sealed with two glass substrates and an active layer $(30 \mu \mathrm{m})$ that consists of a porous $\mathrm{TiO}_{2}(40 \%$ porosity) and dye mixture layer without the electrolyte were prepared on a glass substrate, and transmittance and reflectance of the samples were measured. Optical parameters (the effective refractive index, $\mathrm{n}$ - $\mathrm{k}$ values) of the DSSC active layer were extracted in consideration of $\mathrm{TiO}_{2}$ porosity, which was the result of the iterative process continuing the comparison of the measured transmittance and reflectance spectra with the calculated spectra several times [27]. Using a finite-difference time-domain method (FDTD) with the obtained optical parameters of the DSSC, the absorbance spectra in the active layer and Ag particles for different concentrations of Ag particles were calculated.

\subsection{Fabrication of the FDSSC}

The FDSSCs fabricated here are based on previous experiments [28,29]. A Ti wire was cleaned by deionized water, acetone, and isopropanol alcohol (IPA) sequentially for $10 \mathrm{~min}$ under the sonication. A compact- $\mathrm{TiO}_{2}\left(\mathrm{c}-\mathrm{TiO}_{2}\right)$ layer was formed by electric heating with a current of $1.6 \mathrm{~A}$ for $10 \mathrm{~s}$ in air, allowing the oxidation of Ti wire and oxygen in the air to generate the $\mathrm{c}-\mathrm{TiO}_{2}$ layer. The diluted $\mathrm{TiO}_{2}$ solution $\left(1 \mathrm{~g}\right.$ commercial $\mathrm{TiO}_{2}$ paste and $1 \mathrm{~mL}$ ethanol) was deposited by using the dip-coating technique with $10 \mathrm{~mm} \mathrm{~s}^{-1}$ for the withdraw rate and annealed at $120^{\circ} \mathrm{C}$ for $3 \mathrm{~m}$, and the cycle of dip-coating and annealing process was repeated five times to control the thickness of the $\mathrm{mp}-\mathrm{TiO}_{2}$ layer. The PA layer consisting of the $\mathrm{Ti} / \mathrm{c}-\mathrm{TiO}_{2} / \mathrm{mp}-\mathrm{TiO}_{2}$ layer was then crystallized by electric heating of $2 \mathrm{~A}$ for $10 \mathrm{~m}$ at ambient atmosphere. The PA was immersed in the Y123 dye solution dissolved 
in anhydrous ethanol $(0.1 \mathrm{mM})$ for $4 \mathrm{~h}$. The $\mathrm{CE}$, Pt wire, was wound around the Y123 dye-sensitized PA so as not to damage the Y123 dye-sensitized PA and put into the Teflon tube. Then, after the electrolyte was injected, both ends of the tube were sealed.

\subsection{Liquid Crystal (LC) Layering}

Indium tin oxide (ITO) glass substrates with dimensions of $210 \times 297 \mathrm{~mm}^{2}$ and a sheet resistance of $10 \Omega \mathrm{sq}^{-1}$ were ultrasonically cleaned using a semiconductor cleaning process. Polyimide (PI SE-7492; Nissan Chemical, Tokyo, Japan) was uniformly spin-coated onto the ITO-coated glass substrates to form liquid-crystal (LC) alignment layers. The PI layers were prebaked at $80^{\circ} \mathrm{C}$ for $10 \mathrm{~min}$ and then imidized at $230{ }^{\circ} \mathrm{C}$ for $1 \mathrm{~h}$. The thickness of the PI layer as an insulating film was set to approximately $100 \mathrm{~nm}$. The PI layer was rubbed using a unidirectional rubbing method with a rubbing strength of $300 \mathrm{~mm}$. Twisted-nematic (TN) LC cells were fabricated with a cell gap of $4.2 \mu \mathrm{m}$. To inject positive nematic LCs (MJ001929; ne $=1.5859$, no $=1.4872$, and $\Delta \varepsilon=8.2$, Merck, Darmstadt, German) effectively, a seal pattern was formed to create a vacuum inside the TN LC cell, and a vacuum injection method was used to inject liquid crystals using the capillary phenomenon and pressure difference at room temperature.

\subsection{Characterization}

Field-emission scanning electron microscopy (FE-SEM) images were obtained using a JEOL JSM-6700F field-emission scanning electron microscope (Tokyo, Japan). The optical transmittance was identified via UV-Vis-NIR spectroscopy (Cary 5000, Agilent Technologies, Santa Clara, CA, U.S.). The photocurrent density-voltage $(J-V)$ characteristics of the FDSSCs were obtained by an electrometer (Keithley 2400, Keithley, Cleveland, OH, U.S.) under air-mass (AM) 1.5 illumination $\left(100 \mathrm{~mW} \mathrm{~cm}^{-2}\right)$ provided by a solar simulator (Oriel Sol3A Class AAA solar simulator, models 94043A, Newport, RI, U.S.). The calibrated light intensity was set to 1 sun using a standard silicon cell. The effective area of the device is defined as the project area transmitted by the mask, which is equal to the diameter of the photoanode multiplied by its length $(1 \mathrm{~cm})$. The external quantum efficiency (EQE) was measured using the incident photon-to-current conversion efficiency (IPCE) measurement system (QuantX 300, Oriel, Newport, RI, U.S.) with a $250 \mathrm{~W}$ quartz-tungsten-halogen lamp, an Oriel Cornerstone ${ }^{\mathrm{TM}} 130$ 1/8 m monochromator operated in AC mode, an optical chopper, a lock-in amplifier, and a calibrated Si photodetector. The intensity of the sunlight for outdoor measurements was observed via a UV light meter (TM-208, Tenmars, Neihu, Taiwan). Electrochemical impedance spectroscopy (EIS) measurement was measured with an oscillation amplitude of $15 \mathrm{mV}$ under dark conditions (Bio-Logic VMP-3, SeyssinetPariset, France) by using the open-circuit voltage and the frequency ranges from $1 \mathrm{~Hz}$ to $10 \mathrm{MHz}$. The experimental data were simulated using commercial Z-view software to estimate the values of each component of the corresponding equivalent circuits. The bending test was performed as a function of the number of bending cycles with a bending radius of $10 \mathrm{~mm}$.

\section{Results and Discussion}

The metallic NPs, especially Ag NPs, are traditionally used to enhance the lightharvesting efficiency of optical devices due to their prominent LSPR properties. In addition, due to the unique charge selectivity of peptide receptors in M13 bacteriophage, the metallic NPs can be directly anchored onto the bacteriophage through charge-driven interactions without binder or surfactant [30]. Figure $1 \mathrm{~b}$ shows high-resolution transmission electron microscopy (HR-TEM) (left) to investigate the morphology of Ag@M13 and an energy dispersive X-ray spectroscopy in scanning transmission electron microscopy (EDS-STEM) (right) to investigate its elemental mapping spectra. The nanoscale template of M13 bacteriophage nanostructures was well observed, which consists of nearly spherical NPs smaller than $20 \mathrm{~nm}$ in diameter. In addition, the elemental mapping spectra reveal the presence of the Ag NPs element onto an M13 bacteriophage nanostructure. From these 
results, it is confirmed that the Ag NPs are embedded by maintaining the nanoscale distance well in the bacteriophage template. Hence, the gap-plasmon effect can be expected as the metallic NPs maintain a constant nanoscale distance between them [31,32]. In addition, the gap-plasmon effect can be expected to have an additional effect of amplifying the absorption spectra in a long-wavelength region (about $600 \mathrm{~nm}$ ) along with the existing effect of amplifying the absorption spectra in a short-wavelength region (about $300 \mathrm{~nm}$ ) [33]

The normalized UV-Vis optical absorption spectra of the iodine based electrolytes as a function of the concentration of bare M13 bacteriophage and Ag@M13 bacteriophage are presented in Figure 1c,d, respectively. The electrolytes in which bare M13 bacteriophage (or Ag@M13) are added at concentrations of 5, 10, and $15 \mu \mathrm{L}$ are referred to as M13-5, M13-10, and M13-15 (or Ag@M13-5, Ag@M13-10, and Ag@M13-15), respectively. Reference electrolyte (Ref) and the electrolyte with M13 and Ag@M13 had one absorption band at $370 \mathrm{~nm}$. The absorption spectra of bare M13 bacteriophage increased from M13-5 to M13-10 and then decreased at M13-15. It was confirmed that the bare M13 bacteriophages as a function of the concentration added to the electrolyte hardly change each absorption spectra. In contrast, in the electrolyte to which Ag@M13 was added, it was confirmed that the absorption spectra improved in the long-wavelength region as the concentration of Ag@M13 increased and the full width at half maximum (FWHM) of the absorption band was also widened, as shown in the inset of Figure 1d. The LSPR properties, which are affected by the size of the metallic NPs, are limited to less than about $500 \mathrm{~nm}$ when the size of NPs becomes too small $[30,34]$. This research shows that the normalized absorbance has increased from $400 \mathrm{~nm}$ to the long-wavelength region, which means that the Ag NPs were aligned in a uniform arrangement on nanoscale template of M13 bacteriophage having uniform intervals in nanoscales. Therefore, the plasmonic Ag NPs were uniformly oriented and aligned in nanoscale bacteriophage, which contributed to overcoming the limitation of LSPR in smaller NPs.

The Ag particles included in the DSSC not only increase the absorbance of the active layer by scattering the incident light, which increases the photocurrent of the device, but also absorb the light the Ag particles absorb the light, which cannot contribute to the output photocurrent and lowers the overall photocurrent. Figure 2a shows the plasmonic effects that Ag particles absorb and scatter the light. The Ag particle effects increase with the size as shown in Figure 2b. Here, it is assumed that the size of Ag particles can be randomly distributed between 10-100 nm. As shown in Figure 2c, when the density of Ag particles increases, the amount of the light absorption by the Ag particles increases. In Figure $2 \mathrm{~d}$, when the density of $\mathrm{Ag}$ particles is $\sim 1 \times 10^{9} / \mathrm{mm}^{3}$, the absorption by the active layer can increase in the mid-range of visible light (500-700 nm), but above that concentration, the absorption decreases and even lowers compared to when the Ag is not present, due to the absorption by the Ag particles as shown in Figure 2c [35].

The photovoltaic performance of FDSSCs fabricated with or without improved by Ag@M13 was evaluated by investigating the current density-voltage $(J-V)$ characteristic curves under AM 1.5 illumination, as shown in Figure 3a. In addition, their corresponding photovoltaic parameters are summarized in Table 1. Four parameters for identifying the characteristics of photovoltaic: open-circuit voltage $\left(V_{\mathrm{OC}}\right)$, short-circuit current density ( $\mathrm{SSC}_{\mathrm{SC}}$ ), fill factor $(\mathrm{FF})$, and $\mathrm{PCE}$ are important measures for analyzing the photovoltaic characteristics of FDSSCs. The conditions for FDSSCs in the form of (Ti wire/mp- $\mathrm{TiO}_{2} / \mathrm{Y} 123$ dye/Ag@M13 enhanced electrolyte/Pt wire) are shown in Figure S1. The $V_{\mathrm{OC}}$ increased from 0.65 to $0.66 \mathrm{~V}$ depending on the presence or absence of Ag@M13, but the change is very small. The $V_{\mathrm{OC}}$, which is the gap between the electrolyte and the Fermi level of the photoanode, showed insignificant changes even when Ag@M13 was added. This is interpreted as adding Ag@M13 into the electrolyte not affecting the energy level of the iodine based electrolyte. On one hand, the $J_{\mathrm{SC}}$ and the FF increased from the reference to Ag@M13-10 and then decreased at Ag@M13-15. Overall, the PCEs of FDSSCs enhanced by Ag@M13 enhanced electrolyte were higher than those of the bare electrolyte due to the increase in $J_{\mathrm{SC}}$ and FF. It is considered that the increase in $J_{\mathrm{SC}}$ means that Ag@M13 present 
in the electrolyte has a high probability of penetrating into the dye-sensitized photoanode with the mesoporous structure, which may have caused higher PCE. Furthermore, the increased FF was attributed to the increased shunt resistance $\left(R_{\mathrm{sh}}\right)$, which represents the resistance to recombination, as well as the decreased series resistance $\left(R_{\mathrm{s}}\right)$, which represents the overall resistance of the photoanode. The $R_{\mathrm{s}}$ is ideal for minimizing the decrease in current flow through the solar cell devices as its value is lower. In addition, the $R_{\mathrm{sh}}$ is ideal for preventing the recombination of photoexcited electrons into the electrolyte and maximizing the current flow to the external load as its values is higher. Thus, it is inferred that Ag@M13-10 has the lowest $R_{\mathrm{s}}$ value and the highest $R_{\mathrm{sh}}$ value, which would have affected the higher values of the $J_{\mathrm{SC}}$ and the FF. Hence, the Ag@M13-10 based FDSSC demonstrated the highest PCE of $5.80 \%$ with $J_{\mathrm{SC}}$ of $12.16 \mathrm{~mA} \mathrm{~cm}^{-2}, V_{\mathrm{OC}}$ of $0.66 \mathrm{~V}$, and FF of $72.1 \%$, whereas the bare electrolyte based FDSSC showed a PCE of $4.97 \%$ with $J_{S C}$ of $10.71 \mathrm{~mA} \mathrm{~cm}^{-2}, V_{\mathrm{OC}}$ of $0.65 \mathrm{~V}$, and FF of $71.7 \%$.

(a)

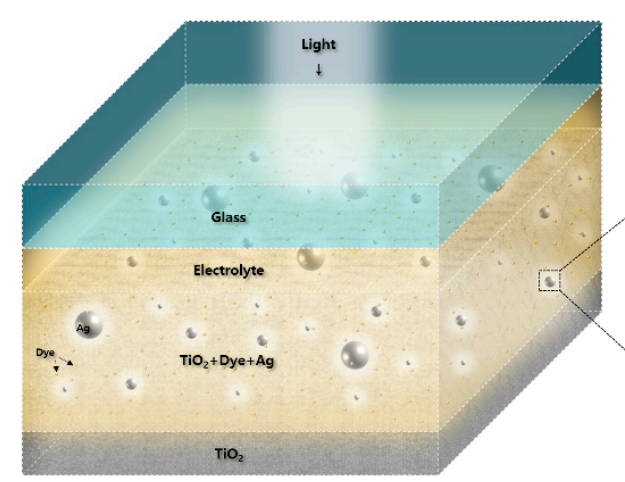

(c)

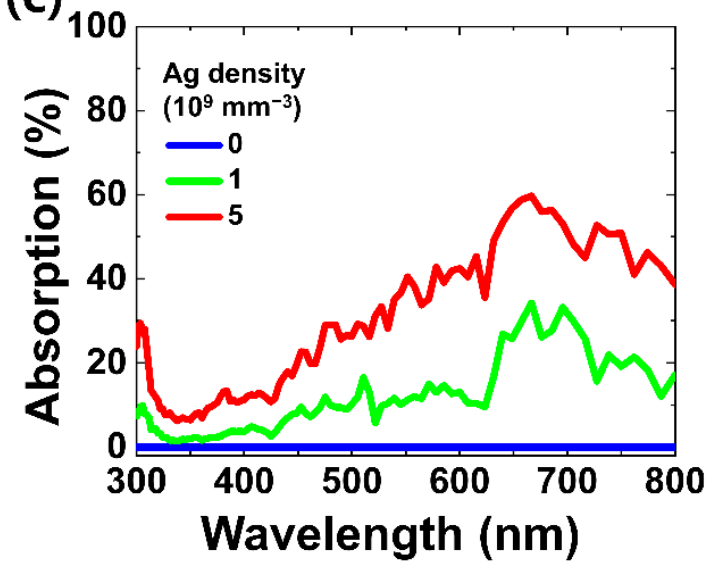

(b)

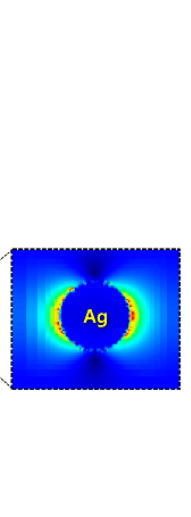

(d)
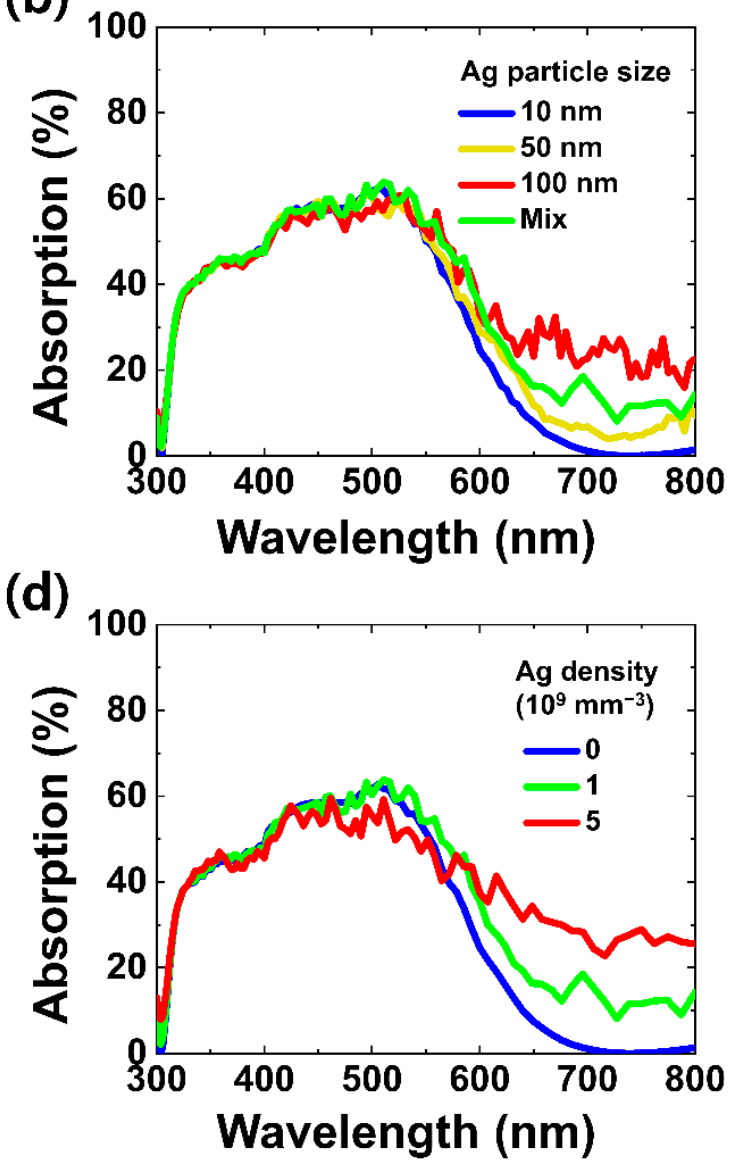

Figure 2. FDTD simulation of Ag-particle effects in the DSSC: (a) illustrated image of DSSC structure, (b) absorption spectra of active layer for the different Ag particle sizes, and absorption at (c) Ag particles and (d) at an active layer for the different Ag densities. 
(a)

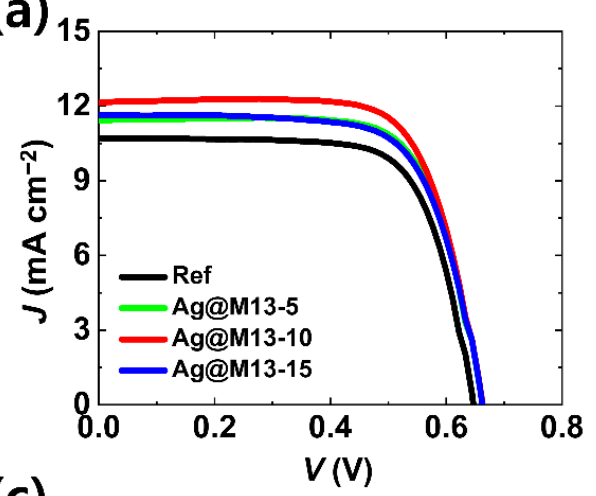

(c)

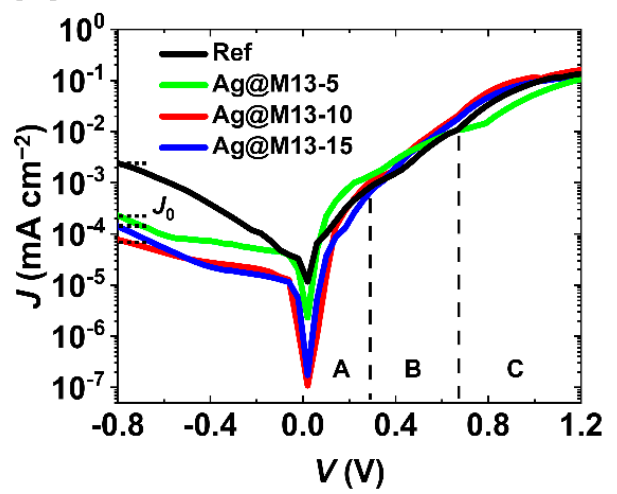

(b)

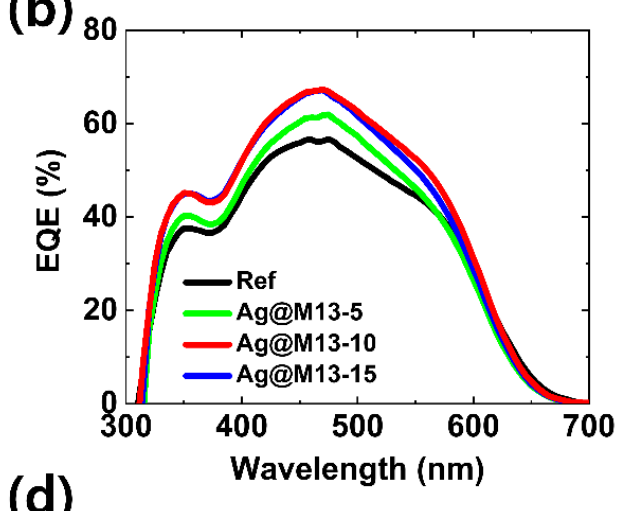

(d)

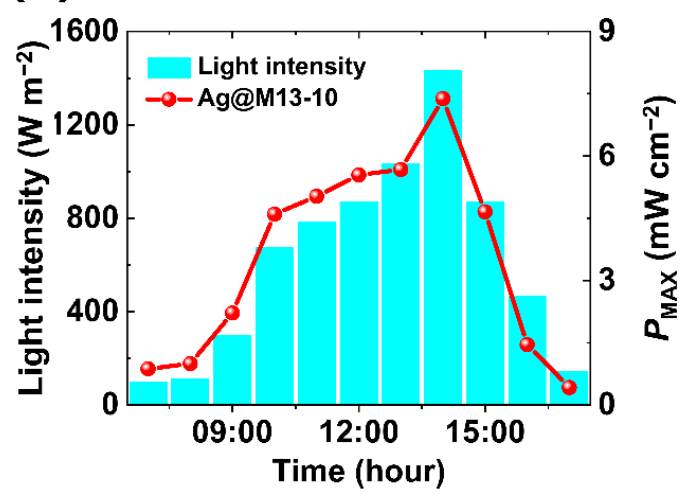

Figure 3. Photovoltaic properties of Ag@M13 enhanced FDSSCs: (a) comparison of $J-V$ curves, (b) the IPCE spectra, (c) dark current profiles of FDSSCs as a function of Ag@M13, respectively, and (d) $P_{\max }$ values over time as an outdoor test.

Table 1. Photovoltaic properties of FDSSCs as a function of Ag@M13.

\begin{tabular}{lcccccc}
\hline & $\begin{array}{c}V_{\text {OC }} \\
(\mathbf{V})\end{array}$ & $\begin{array}{c}J_{\text {SC }} \\
(\mathbf{m A ~ c m}\end{array}$ & $\begin{array}{c}\text { FF } \\
\mathbf{( \% )}\end{array}$ & $\begin{array}{c}\text { PCE } \\
(\mathbf{\%})\end{array}$ & $\begin{array}{c}\boldsymbol{R}_{\mathbf{s}} \\
\left(\mathbf{\Omega} \mathbf{~ c m}^{\mathbf{2}}\right)\end{array}$ & $\begin{array}{c}\boldsymbol{R}_{\mathbf{s h}} \\
\left(\boldsymbol{\Omega} \mathbf{~ c m}^{\mathbf{2}}\right)\end{array}$ \\
\hline Ref & 0.65 & 10.71 & 71.7 & 4.97 & 7.13 & $6.97 \times 10^{4}$ \\
Ag@M13-5 & 0.66 & 11.44 & 71.8 & 5.47 & 5.36 & $8.90 \times 10^{4}$ \\
Ag@M13-10 & 0.66 & 12.16 & 72.1 & 5.80 & 4.32 & $1.26 \times 10^{5}$ \\
Ag@M13-15 & 0.66 & 11.61 & 69.9 & 5.39 & 5.29 & $9.43 \times 10^{4}$ \\
\hline
\end{tabular}

The external quantum efficiency (EQE) spectra of the FDSSCs as a function of the concentration of Ag@M13 were investigated, and the results are shown in Figure 3b. In particular, the optimized Ag@M13-10 enhanced FDSSC showed a higher maximum EQE response than the other devices, which is consistent with the $J_{S C}$ value in the $J-V$ curve. The results shown $J-V$ curves and EQDs above coherently demonstrate that there were more efficient charge extraction and less charge recombination in the Ag@M13 enhanced FDSSCs that the bare FDSSC. The improved performance by Ag@M13 enhanced electrolyte based FDSSCs benefited from the synergistic interaction between the plasmonic Ag NPs and M13 bacteriophages caused by the gap-plasmon effect amplified by the Ag NPs-embedded M13 bacteriophage nanostructures.

The dark $J-V$ curves in Figure $3 c$ show that the dark current curve slope varies as the voltage increases, which reflects different physical mechanisms. A, B, and C areas of the dark current have been reported to be associated with the shunt, recombination, and diffusion currents, respectively. In the A area, the dark current was mainly affected by the shunt current under a small applied bias voltage. It is shown that the $R_{\text {sh }}$ value of Ag@M13-10 at the lowest slope in area $\mathrm{A}$ is very consistent with the $R_{\mathrm{sh}}$ value obtained from $J-V$ curves in Figure $3 a$. As the bias voltage increases, the recombination current 
gradually increases similar to the diffusion current in the dark $J-V$ characteristics, as shown in area B. It can be seen that the slope of area B increases more gently than that of area $C$. Moreover, the current increase in the area $C$ is caused by the diffusion-dominated current. Indeed, in an area C higher than the built-in potential of DSSCs (about $0.7 \mathrm{~V}$ ), the effect on the recombination current is negligible, and the curve is dominated only by the diffusion current limited by the $R_{\mathrm{S}}$ of the device [36]. Therefore, the Ag@M13 enhanced FDSSCs indicates that the leakage current decreased and the charge extraction and transport efficiency improved due to the relatively increased $R_{\mathrm{sh}}$ and decreased recombination current. Furthermore, the dark current density $\left(J_{0}\right)$ of the FDSSCs, which fabricated Ag@M13 as a function of concentration, was smaller than those of the bare electrolyte. This can be inferred as a phenomenon indicating that the dark current density was decreased due to the rapid transport of photoexcited electrons by the presence of Ag@M13 [37].

Power generation of wearable fiber electronic solar cells that depending on the daylight intensity should be considered for further development. Figure $3 \mathrm{~d}$ shows the maximum power $\left(P_{\mathrm{MAX}}\right)$ values corresponding to the time-dependent change of sunlight in an outdoor environment to evaluate the characteristics of the wearable applications. The $P_{\mathrm{MAX}}$ values of the Ag@M13 enhanced FDSSCs were verified by the following equation: $P_{\mathrm{MAX}}=I \times V \times \mathrm{FF}$. The sunlight intensity increased from the initial $400 \mathrm{~W} \mathrm{~m}^{-2}$ at 9:00 a.m. to $1400 \mathrm{~W} \mathrm{~m}^{-2}$ at 2:00 p.m., when the sun's altitude reached its highest point. The light intensity gradually decreased to under $200 \mathrm{~W} \mathrm{~m}^{-2}$ at 5:00 p.m. As expected, the timedependent change in daylight intensity and the corresponding $P_{\mathrm{MAX}}$ values of the solar cell devices showed the equivalent tendency.

EIS was performed under dark conditions at a bias voltage of $0.7 \mathrm{~V}$ in the frequency range of $0.1 \mathrm{~Hz}-1 \mathrm{MHz}$ to accurately analyze the interfacial dynamics for the charge transfer behavior in Ag@M13 enhanced FDSSCs, as shown in the Nyquist plots in Figure 4a. The Nyquist plots simulated by the equivalent circuit diagram, as shown in Figure S2. The equivalent circuit, $R_{\mathrm{s}}+\left(\mathrm{CPE}_{\mathrm{ct} 1} / / R_{\mathrm{ct} 1}\right)+\left(\mathrm{CPE}_{\mathrm{ct} 2} / / R_{\mathrm{ct} 2}\right)$, consists of a series resistance $\left(R_{\mathrm{s}}\right)$ and two charge-transfer resistances. The $R_{\mathrm{ct} 1}$ and $R_{\mathrm{ct} 2}$, which mean charge transfer resistance, are represented by the first smaller half-circle in the high-frequency region and the second larger half circle in the low-frequency region, respectively. These values are interpreted as interfacial resistance between $\mathrm{CE}$ /electrolyte and interfacial resistance between dye-sensitized PA/electrolyte, respectively. Moreover, the $\mathrm{CPE}_{\mathrm{ct} 1}$ and $\mathrm{CPE}_{\mathrm{ct} 2}$ represent the constant-phase elements for interfaces at $\mathrm{CE} /$ electrolyte and dye-sensitized PA/electrolyte, respectively [38]. The fitting values of $R_{\mathrm{S}}$, which is related to the transfer resistance of the photoanode, were 7.49, 6.85, 4.57, and $5.16 \Omega$ for the Ref, Ag@M13-5, Ag@M13-10, and Ag@M13-15 enhanced FDSSCs, respectively, as shown in the inset of Figure $4 \mathrm{a}$ and Table 2 . This tendency was very consistent with the $R_{\mathrm{S}}$ values obtained from the aforementioned $J-V$ characteristic curves, and it can be seen that the $R_{\mathrm{S}}$ value is the lowest in Ag@M13-10 enhanced FDSSC. The $R_{\mathrm{ct} 1}$ values showed very slight difference from $24.30 \Omega$ at the Ag@M13-10 enhanced FDSSC, the lowest value, to $26.99 \Omega$ at the Ref-FDSSC, the highest value. This tendency is also shown in $\mathrm{CPE}_{\mathrm{ct} 1}$. These results are interpreted that the Ag@M13 bacteriophages added to the electrolyte were not significantly correlated with CE. On the other hand, the $R_{\mathrm{ct} 2}$ values representing the interfacial resistance between dye-sensitized PA/electrolyte were 129.0, 117.2, 53.1, and $75.8 \Omega$ for the Ref, Ag@M13-5, Ag@M13-10, and Ag@M13-15 enhanced FDSSCs, respectively, showing clear difference. The lowest $R_{\mathrm{s}}, R_{\mathrm{ct} 1}$, and $R_{\mathrm{ct} 2}$ values observed for the Ag@M13-10 enhanced FDSSCs are most probably the consequence of the faster charge-transport process arising from the high probability that Ag@M13 penetrates into the dye-sensitized PA with the mesoporous structure, as mentioned above. Based on the improved charge transfer characteristics at the dye-sensitized PA/electrolyte interface, it can be confirmed that all the key parameters of the Ag@M13-10 enhanced FDSSCs could be enhanced, which resulted in high $J_{S C}$ and PCE. 
(a)

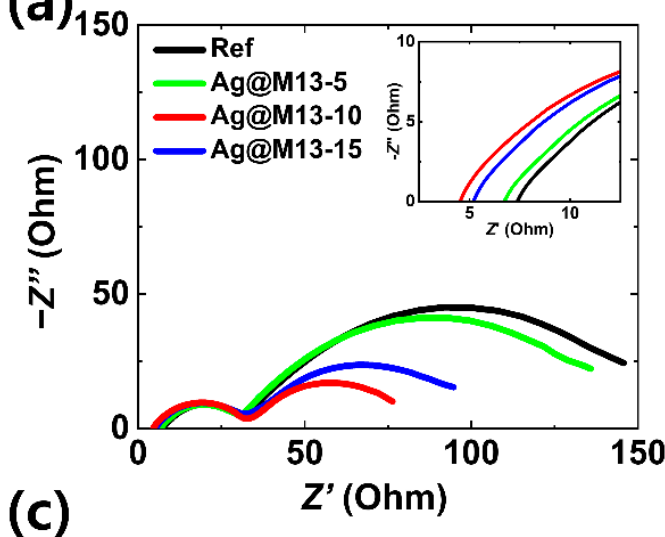

(b)
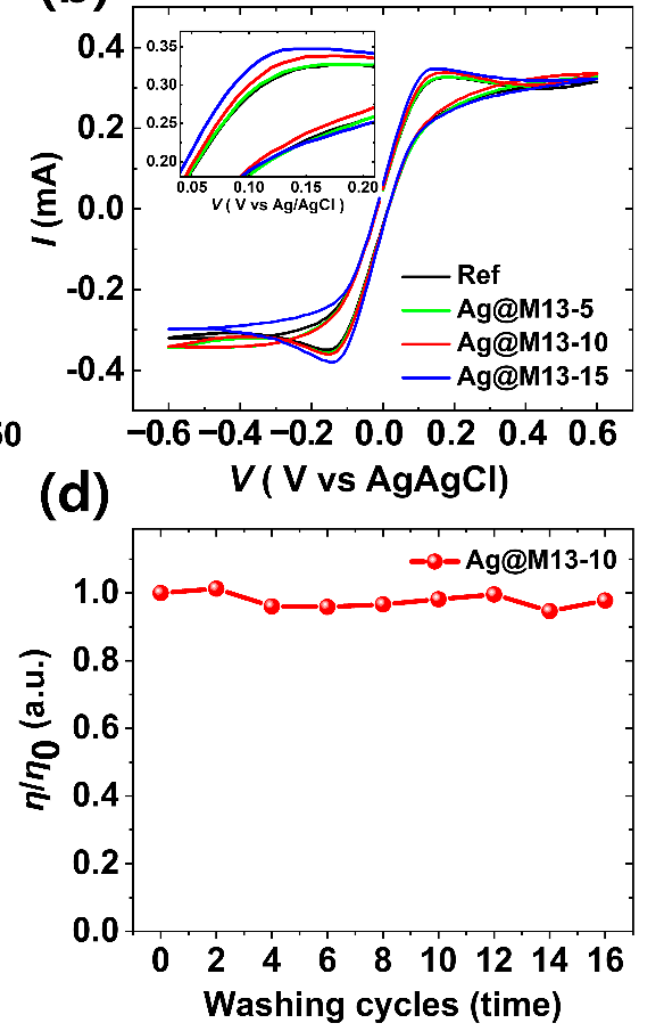

Figure 4. Electrochemical properties of the Ag@M13 enhanced FDSSCs: (a) Nyquist plots and onset point of Nyquist plots in the high-frequency region (inset), (b) CV characteristics. The three-electrode system, measured at a scan rate of $200 \mathrm{mV} \mathrm{s}^{-1}$, contains an $\mathrm{Ag} / \mathrm{AgCl}$ as a reference electrode, $\mathrm{Pt}$ wires as working and counter electrodes, respectively. Normalized $\eta / \eta_{0}$ of Ag@M13-10 enhanced FDSSCs as a function of (c) bending cycles and (d) washing cycles. The inset in Figure $4 \mathrm{c}$ is the normalized $\eta / \eta_{0}$ under extreme bending conditions, such as radii $2.5,5.0$, and $7.5 \mathrm{~mm}$.

Table 2. EIS parameters of SS-FDSSCs as a function of Ag@M13.

\begin{tabular}{lccccc}
\hline & $\begin{array}{c}\boldsymbol{R}_{\mathbf{s}} \\
(\boldsymbol{\Omega})\end{array}$ & $\begin{array}{c}\boldsymbol{R}_{\mathrm{ct1}} \\
(\boldsymbol{\Omega})\end{array}$ & $\begin{array}{c}\mathrm{CPE}_{\mathrm{ct} 1} \\
\mathbf{( F )}\end{array}$ & $\begin{array}{c}\boldsymbol{R}_{\mathrm{ct} 2} \\
(\boldsymbol{\Omega})\end{array}$ & $\begin{array}{c}\mathbf{C P E}_{\mathrm{ct} 2} \\
\mathbf{( F )}\end{array}$ \\
\hline Ref & 7.49 & 26.99 & $4.68 \times 10^{-5}$ & 129.2 & $2.51 \times 10^{-3}$ \\
$\mathrm{Ag} @ \mathrm{M} 13-5$ & 6.85 & 26.24 & $4.66 \times 10^{-5}$ & 117.2 & $2.75 \times 10^{-3}$ \\
$\mathrm{Ag} @ \mathrm{M} 13-10$ & 4.57 & 24.30 & $3.01 \times 10^{-5}$ & 53.1 & $8.37 \times 10^{-3}$ \\
$\mathrm{Ag} @ \mathrm{M} 13-15$ & 5.16 & 25.01 & $4.27 \times 10^{-5}$ & 75.8 & $5.74 \times 10^{-3}$ \\
\hline
\end{tabular}

Catalytic activities and reaction kinetics of the Ag@M13 enhanced electrolyte were investigated by electrochemical characterization using cyclic voltammetry $(\mathrm{CV})$ measurement, as shown in Figure $4 \mathrm{~b}$. The CV measurement of the enhanced electrolyte as a function of Ag@M13 was based on a three-electrode system consisting of two Pt wire electrodes as the working and counter electrode, respectively, and an $\mathrm{Ag} / \mathrm{AgCl}$ as the reference electrode. The CV measurement was performed under the same conditions of applying the $\mathrm{Pt}$ wire as a working electrode and a counter electrode, and the analysis was focused on the catalytic properties of Ag@M13 injected into the electrolyte. The electrolyte used for CV was proceeded under the same condition as the electrolyte in the solar cell, and was used by adding 5,10 , and $15 \mu \mathrm{L}$ of Ag@M13 to HPE. A pair of oxidation and reduction peaks 
can be identified, which corresponds to cathodic and anodic peaks indicated by reduction (Equation (1)) and oxidation (Equation (2)) reactions of iodide/triiodide, respectively [39]:

$$
\begin{aligned}
& I_{3}^{-}+2 e^{-} \leftrightarrow 3 I^{-} \\
& 3 I^{-} \leftrightarrow 2 e^{-}+I_{3}^{-}
\end{aligned}
$$

Although the distribution and morphological shape of the peaks are not significantly different under all conditions, the intensity of the peak increased as the concentration of Ag@M13 increased, as shown in the inset of Figure 4b. This suggests that the interaction between Ag@M13 added to the electrolyte and CE is not large, but it can be considered that the injection of Ag@M13 into the electrolyte contributed to the catalytic activity to some extent. Thus, Ag@M13 added to the electrolyte exhibits higher current density on both the oxidation and reduction characteristics, indicating efficient charge transfer due to improved catalytic activities.

Weaving ability, durability, and water resistance are very important parameters in wearable device applications. The Ag@M13-10 enhanced FDSSCs exhibited excellent mechanical durability, as shown in Figure $4 \mathrm{c}$. It can be seen that the normalized $\eta / \eta_{0}$ of the Ag@M13-10 enhanced FDSSCs with a radius of about $10 \mathrm{~mm}$ showed a slight degradation in change to almost $80 \%$ even after 350 bending cycles. Even under extreme bending conditions such as radii $2.5,5.0$, and $7.5 \mathrm{~mm}$, the normalized $\eta / \eta_{0}$ was maintained without significant reduction, as shown in the inset of Figures 4c and S3. Furthermore, the Ag@M1310 enhanced FDSSCs exhibited excellent water resistance, as shown in Figure 4d. Repeated washing tests of Ag@M13-10 enhanced FDSSC were performed with an automatic cleaner, as shown in Figure S4. It was confirmed that the normalized $\eta / \eta_{0}$ of the Ag@M13-10 enhanced FDSSC hardly decreased even after repeating the 16 iterations of the washing tests. These results indicate that Ag@M13 enhanced FDSSCs have excellent characteristics as wearable electronic devices. On the other hand, the Ag@M13 enhanced FDSSCs were connected in series and parallel to drive a liquid-crystal (LC) device for smart windows such as indoor lighting, as shown in Figure S5. The voltage and current density generated by the series and parallel connections of the Ag@M13 enhanced FDSSCs were about $2.3 \mathrm{~V}$ and $1.8 \mu \mathrm{A}$ under indoor lighting of $172.8 \mathrm{~W} \mathrm{~m}^{-2}$, respectively, generating sufficient power for the operation of the LC device.

\section{Conclusions}

In conclusion, the Ag metallic NPs embedded M13 bacteriophages with the improved LSPR properties were supplemented to the electrolyte of the FDSSCs. It was confirmed that the Ag@M13 enhanced electrolyte showed high absorbance in a long wavelength region of $500 \mathrm{~nm}$ or more, and that the plasmonic Ag NPs were uniformly oriented and aligned in nanoscale M13 bacteriophages. The FDSSCs were fabricated using an Ag@M13 enhanced electrolyte, which was demonstrated to improve the PCE by plasmonic enhancement effect. The optimized Ag@M13 enhanced FDSSC boasts effective electron extraction, unidirectional electron transportation, and suppressed charge recombination processes, resulting in a PCE of up to $5.80 \%$, which was improved by $16.7 \%$ compared to that of the reference device with 4.97\%. In addition, the Ag@M13 enhanced FDSSCs maintained the PCE of $>80 \%$ over 350 cycles of bending tests and $>90 \%$ over 16 repetitions of washing tests.

Supplementary Materials: Supplementary materials are available in the online version of the article at https:/ / www.mdpi.com/article/10.3390/nano11123421/s1. Figure S1, Schematic diagram of the fabrication process of the FDSSCs; Figure S2, The equivalent circuit for EIS; Figures S3 and S4, Further details of photographs on bending and washing tests; Figure S5, Application driving photograph using FDSSCs.

Author Contributions: Conceptualization of idea, synthesis, S.-J.K. and J.H.K.; overall manuscript writing and analysis of results, J.H.K. and J.W.C.; FDTD simulation, Y.-K.K., M.S. (Myunghun Shin); 
TEM analysis, J.-W.O.; review and editing, H.W.L. and J.-W.O.; supervision, M.S. (Myungkwan Song). All authors have read and agreed to the published version of the manuscript.

Funding: This research was supported by the Fundamental Research Program (PNK 7350) of the Korea Institute of Materials Science (KIMS) and by a National Research Foundation (NRF) grant funded by the Korean government (MEST) (2019M3D1A1067389).

Data Availability Statement: Not applicable.

Conflicts of Interest: The authors declare no conflict of interests.

\section{References}

1. Sun, H.; Li, H.; You, X.; Yang, Z.; Deng, J.; Qiu, L.; Peng, H. Quasi-solid-state, coaxial, fiber-shaped dye-sensitized solar cells. J. Mater. Chem. A 2014, 2, 345-349. [CrossRef]

2. Song, W.; Wang, H.; Liu, G.; Peng, M.; Zou, D. Improving the photovoltaic performance and flexibility of fiber-shaped dyesensitized solar cells with atomic layer deposition. Nano Energy 2016, 19, 1-7. [CrossRef]

3. Fu, X.; Sun, H.; Xie, S.; Zhang, J.; Pan, Z.; Liao, M.; Xu, L.; Li, Z.; Wang, B.; Sun, X.; et al. A fiber-shaped solar cell showing a record power conversion efficiency of 10\%. J. Mater. Chem. A 2018, 6, 45-51. [CrossRef]

4. Liu, G.; Wang, M.; Wang, H.; Ardhi, R.E.A.; Yu, H.; Zou, D.; Lee, J.K. Hierarchically structured photoanode with enhanced charge collection and light harvesting abilities for fiber-shaped dye-sensitized solar cells. Nano Energy 2018, 49, 95-102. [CrossRef]

5. Zhang, J.; Wang, Z.; Li, X.; Yang, J.; Song, C.; Li, Y.; Cheng, J.; Guan, Q.; Wang, B. Flexible Platinum-Free Fiber-Shaped Dye Sensitized Solar Cell with 10.28\% Efficiency. ACS Appl. Energy Mater. 2019, 2, 2870-2877. [CrossRef]

6. Utomo, D.S.; Kim, J.H.; Lee, D.; Park, J.; Kang, Y.-C.; Kim, Y.H.; Choi, J.W.; Song, M. Fractional structured molybdenum oxide catalyst as counter electrodes of all-solid-state fiber dye-sensitized solar cells. J. Colloid Interface Sci. 2021, 584, 520-527. [CrossRef] [PubMed]

7. Kim, J.H.; Utomo, D.S.; Lee, D.; Choi, J.W.; Song, M. Catalytic fower-shaped $\alpha-\mathrm{MoO}_{3}$ lamellar structure for solid-state fiber-dyesensitized solar cells. J. Power Sources 2021, 512, 230496. [CrossRef]

8. Joshi, P.; Zhang, L.; Davoux, D.; Zhu, Z.; Galipeau, D.; Fong, H.; Qiao, Q. Composite of $\mathrm{TiO}_{2}$ nanofibers and nanoparticles for dye-sensitized solar cells with significantly improved efficiency. Energy Environ. Sci. 2010, 3, 1507-1510. [CrossRef]

9. Elbohy, H.; Kim, M.R.; Dubey, A.; Reza, K.M.; Ma, D.; Zai, J.; Qian, X.; Qiao, Q. Incorporation of plasmonic Au nanostars into photoanodes for high efficiency dye-sensitized solar cells. J. Mater. Chem. A 2016, 4, 545-551. [CrossRef]

10. Sharma, K.; Sharma, V.; Sharma, S.S. Dye-Sensitized Solar Cells: Fundamentals and Current Status. Nanoscale Res. Lett. 2018, 13, 381. [CrossRef]

11. Gao, F.; Wang, W.; Shi, D.; Zhang, J.; Wang, M.; Jing, X.; Humphry-Baker, R.; Wang, P.; Zakeeruddin, S.M.; Grätzel, M. Enhance the Optical Absorptivity of Nanocrystalline $\mathrm{TiO}_{2}$ Film with High Molar Extinction Coefficient Ruthenium Sensitizers for High Performance Dye-Sensitized Solar Cells. J. Am. Chem. Soc. 2008, 130, 10720-10728. [CrossRef] [PubMed]

12. Atwater, H.A.; Polman, A. Plasmonics for improved photovoltaic devices. Nat. Mater. 2010, 9, 205-213. [CrossRef]

13. Barnes, W.L.; Dereux, A.; Ebbesen, T.W. Surface plasmon subwavelength optics. Nature 2003, 424, 824-830. [CrossRef]

14. Schuller, J.A.; Barnard, E.S.; Cai, W.; Jun, Y.C.; White, J.S.; Brongersma, M.L. Plasmonics for extreme light concentration and manipulation. Nat. Mater. 2010, 9, 193-204. [CrossRef] [PubMed]

15. Green, M.A.; Pillai, S. Harnessing plasmonics for solar cells. Nat. Photonics. 2012, 6, 130-132. [CrossRef]

16. Butler, J.C.; Angelini, T.; Tang, J.X.; Wong, G.C.L. Ion Multivalence and Like-Charge Polyelectrolyte Attraction. Phys. Rev. Lett. 2003, 91, 028301. [CrossRef]

17. Petrenko, V.A.; Smith, G.P. Phages from landscape libraries as substitute antibodies. Protein Eng. 2000, 13, 589-592. [CrossRef]

18. Petrenko, V.A.; Vodyanoy, V.J. Phage display for detection of biological threat agents. J. Microbiol. Methods. 2003, 53, 253-262. [CrossRef]

19. Royston, E.; Lee, S.-Y.; Culver, J.N.; Harris, M.T. Characterization of silica-coated tobacco mosaic virus. J. Colloid Interface Sci. 2006, 298, 706-712. [CrossRef]

20. Bruckman, M.A.; Kaur, G.; Lee, L.A.; Xie, F.; Sepulveda, J.; Breitenkamp, R.; Zhang, X.; Joralemon, M.; Russell, T.P.; Emrick, T.; et al. Surface Modificaion of Tobacco Mosaic Virus with "Click" Chemistry. ChemBioChem. 2008, 9, 519-523. [CrossRef]

21. Scibilia, S.; Lentini, G.; Fazio, E.; Franco, D.; Neri, F.; Mezzasalma, A.M.; Guglielmino, S.P.P. Self-assembly of silver nanoparticles and bacteriophage. Sens. Bio-Sens. Res. 2016, 7, 146-152. [CrossRef]

22. Lentini, G.; Fazio, E.; Calabrese, F.; De Plano, L.M.; Puliafico, M.; Franco, D.; Nicolò, M.S.; Carnazza, S.; Trusso, S.; Allegra, A.; et al. Phage-AgNPs complex as SERS probe for U937 cell identification. Biosens. Bioelectron. 2015, 74, 398-405. [CrossRef] [PubMed]

23. Brown, M.D.; Parkinson, P.; Torres, T.; Miura, H.; Herz, L.M.; Snaith, H.J. Surface Energy Relay Between Consensitized Molecules in Solid-State Dye-Sensitized Solar Cells. J. Phys. Chem. C 2011, 115, 23204-23208. [CrossRef]

24. Choi, H.; Chen, W.T.; Kamat, P.V. Know Thy Nano Neighbor. Plasmonic versus Electron Charging Effects of Metal Nanoparticles in Dye-Sensitized Solar Cells. ACS Nano 2012, 6, 4418-4427. [CrossRef]

25. Isah, K.U.; Jolayemi, B.J.; Ahmadu, U.; Kimpa, M.I.; Alu, N. Plasmonic effect of silver nanoparticles intercalated into mesoporous betalain-sensitized-TiO ${ }^{2}$ film electrodes on photovoltaic performance of dye-sensitized solar cells. Mater. Renew. Sustain. Energy. 2016, 5, 10. [CrossRef] 
26. Franco, D.; De Plano, L.M.; Rizzo, M.G.; Scibilia, S.; Lentini, G.; Fazio, E.; Neri, F.; Guglielmino, S.P.P.; Mezzasalma, A.M. Bio-hybrid gold nanoparticles as SERS probe for rapid bacteria cell identification. Spectroc. Acta Pt. A-Molec. Biomolec. Spectr. 2020, 224, 117394. [CrossRef] [PubMed]

27. Kim, H.; Jo, J.; Lee, G.; Shin, M.; Lee, J.-C. Optical Modeling of Dye-Sensitized Solar Cells for Color Analysis. J. Nanosic. Nanotechnol. 2017, 17, 8425-8431. [CrossRef]

28. Kim, J.H.; Koo, S.-J.; Cho, H.; Choi, J.W.; Ryu, S.Y.; Kang, J.-W.; Jin, S.-H.; Ahn, C.; Song, M. 6.16\% Efficiency of Solid-State Fiber Dye-Sensitized Solar Cells Based on LiTFSI Electrolytes with Novel TEMPOL Derivatives. ACS Sustain. Chem. Eng. 2020, 8, 15065-15071. [CrossRef]

29. Kim, J.H.; Hong, S.K.; Yoo, S.-J.; Woo, C.Y.; Choi, J.W.; Lee, D.; Kang, J.-W.; Lee, H.W.; Song, M. Pt-free, cost-effective and efficient counter electrode with carbon nanotube yarn for solid-state fiber dye-sensitized solar cells. Dyes Pigment. 2021, 185, 108855. [CrossRef]

30. Lee, H.B.; Kim, W.-G.; Lee, M.; Lee, J.-M.; He, S.; Kumar, N.; Devaraj, V.; Choi, E.J.; Jeon, I.; Song, M.; et al. Gap Plasmon of Virus-Templated Biohybrid Nanostructures Uplifting the Performance of Organic Optoelectronic Devices. Adv. Optical Mater. 2020, 8, 1902080. [CrossRef]

31. Zhang, Y.; Zhen, Y.-R.; Neumann, O.; Day, J.K.; Nordlander, P.; Halas, N.J. Coherent anti-Stokes Raman scattering with singlemolecule sensitivity using a plasmonic Fano resonance. Nat. Commun. 2014, 5, 4424. [CrossRef]

32. Yi, C.; Dongare, P.D.; Su, M.-N.; Wang, W.; Chakraborty, D.; Wen, F.; Chang, W.-S.; Sader, J.E.; Nordlander, P.; Halas, N.J.; et al. Vibrational coupling in plasmonic molecules. Proc. Natl. Acad. Sci. USA 2017, 114, 11621-11626. [CrossRef]

33. Li, G.; Chang, W.-H.; Yang, Y. Low-bandgap conjugated polymers enabling solution-processable tandem solar cells. Nat. Rev. Mater. 2017, 2, 17043. [CrossRef]

34. Jang, Y.H.; Jang, Y.J.; Kochuveedu, S.T.; Byun, M.; Lin, Z.; Kim, D.H. Plasmonic dye-sensitized solar cells incorporated with $\mathrm{Au}-\mathrm{TiO}_{2}$ nanostructures with tailored configurations. Nanoscale 2014, 6, 1823-1832. [CrossRef]

35. Topič, M.; Čampa, A.; Filipič, M.; Berginc, M.; Krašovec, U.O.; Smole, F. Optical and electrical modelling and characterization of dye-sensitized solar cells. Curr. Appl. Phys. 2010, 10, S425-S430.

36. Liao, P.; Zhao, X.; Li, G.; Shen, Y.; Wang, M. A New Method for Fitting Current-Voltage Curves of Planar Heterojunction Perovskite Solar Cells. Nano-Micro Lett. 2018, 10, 5. [CrossRef] [PubMed]

37. Peng, H.; Sun, X.; Weng, W.; Fang, X. Energy Harvesting Based on Polymer. In Polymer Materials for Energy and Electronic Applications, 1st ed.; Academic Press: Cambridge, MA, USA, 2017; pp. 151-196.

38. Kim, J.H.; Yoo, S.-J.; Lee, D.; Choi, J.W.; Han, S.-C.; Ryu, T.I.; Lee, H.W.; Shin, M.; Song, M. Highly efficient and stable solid-state fiber dye-sensitized solar cells with Ag-decorated $\mathrm{SiO}_{2}$ nanoparticles. Nano Res. 2021, 14, 2728-2734. [CrossRef]

39. Shukla, S.; Loc, N.H.; Boix, P.P.; Koh, T.M.; Prabhakar, R.R.; Mulmudi, H.K.; Zhang, J.; Chen, S.; Ng, C.F.; Huan, C.H.A.; et al. Iron Pyrite Thin Film Counter Electrodes for Dye-Sensitized Solar Cells: High Efficiency for Iodine and Cobalt Redox Electrolyte Cells. ACS Nano 2014, 8, 10597-10605. [CrossRef] 